Journal of English Language Teaching and Applied Linguistics

ISSN: 2707-756X

DOI: $10.32996 /$ jeltal

Journal Homepage: www.al-kindipublisher.com/index.php/jeltal

JELTAL

\title{
Attitude and Motivation in Language Learning: A Review
}

\author{
Pham Duc Thuan 8(D) \\ MA, English Teacher, Department of Foreign Languges and Information Technology, Hoa Lu University, Ninh Binh Province, Viet \\ Nam
}

$\triangle$ Corresponding Author: Pham Duc Thuan, E-mail: pdthuan@hluv.edu.vn

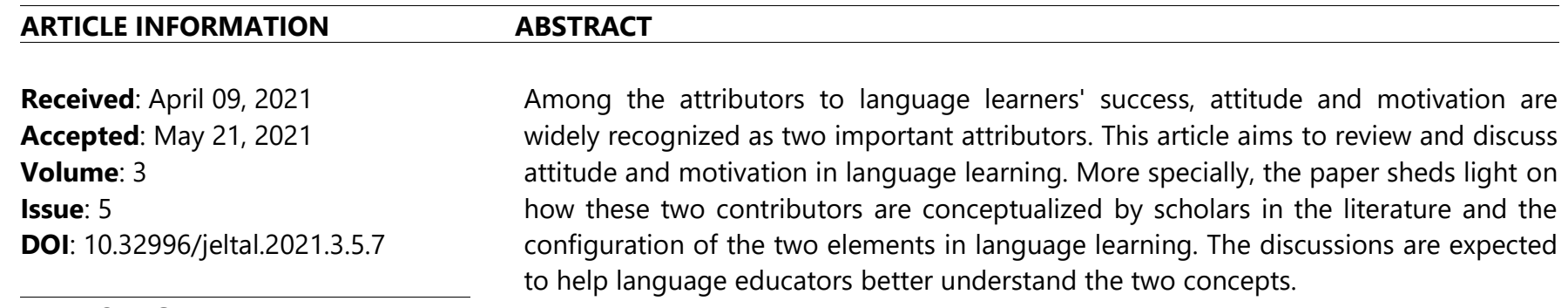

\section{KEYWORDS}

Attitude, motivation, language

learning

\section{Introduction}

Attitude and motivation are considered two major attributes that influence how well a student learns a language. Defined traditionally, attitude is a complex and durable tendency that predisposes the individual to act in a certain way. Cakici (2007) states: "as a socio-psychological factor, the role of attitude on the language learning process should be taken into consideration" (p.23). Kudo (1999) concludes that attitudes may play an essential role in language learning, as they would appear to influence students' success or failure in their learning. Klausmeier (1985), similarly, notes that attitudes influence how well students learn and how well they behave. Gardner (1985) believes that learners' attitudes toward learning the target language are expected to be more relevant to obtaining a high grade in target language proficiency than learners' interest in learning a foreign language or the people who speak the target language. Cakici (2007) argues that the learners' positive attitudes towards a language, towards the culture of that community make the learning process easier, but an unfavourable attitude hinders learning.

According to Liu (2007), motivation to learn a second language is grounded in positive attitudes toward the second language community and a desire to communicate with valued community members and become similar to them. The desire is integrative motivation, which is better support for language learning, while instrumental motivation is associated with a desire to learn a second language for pragmatic gains such as getting a better job or a higher salary. Motivation plays the role to help lead to a set of goals, either with a strong interpersonal quality (integrative motivation) or a strong practical quality (instrumental motivation) (Dörnyei, 1994).

As empirical studies on language learning motivation blossom, it has been found integrative and instrumental motivations are not opposite ends of a continuum (Dörnyei, 1994). Instead, they are positively related, and both are effectively loaded goals that can sustain learning. They both maybe, in return, enhanced by better proficiency and higher achievement in the target language (Dörnyei, 1994). Students' learning goals also proved to break up into different motivation clusters, the definition of which varies depending upon the socio-cultural setting in which the data are gathered (Clement et al., 1994). Thus, new motivation clusters have been identified, such as intrinsic and extrinsic motivations which were proposed in self-determination theory. "Intrinsic motivation refers to doing something because it is inherently interesting or enjoyable, and extrinsic motivation refers to doing something because it leads to a separable outcome and because of external rewards" (Ryan \& Deci, 2000, p.55). When a learner has no extrinsic or intrinsic goals for learning a language, demotivation arises, which refers to the state of lacking an intention to

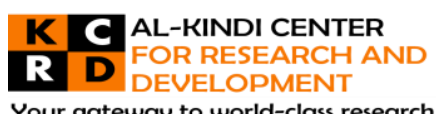

Your gateway to world-class research

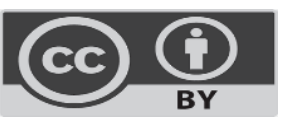

Published by Al-Kindi Center for Research and Development, United Kingdom. Copyright (c) the author(s). This open access article is distributed under a Creative Commons Attribution (CC-BY) 4.0 license 
act (Ryan \& Deci, 2000). As these concepts have gained popularity, it is claimed that intrinsic motivation plays a central role in learning a second/foreign language (Liu, 2007).

In conclusion, both integrative/instrumental motivations and intrinsic/extrinsic motivations contribute to learning a second/foreign language. Nevertheless, which one is more important varies from context to context. Likewise, students in different contexts may be motivated to learn a second/foreign language by different motivation type. This is why the issue is still worth further exploration.

\section{Attitude and motivation in language learning}

\subsection{Factors affecting 12 learning in socio-educational model}

Many studies have been carried out in the field of second or foreign language (L2) learning, which explains the factors affecting L2 language learning. Gardner's Socio-educational Model is the most distinguishable work from most research into language learning. The model was first presented in 1979 (Jenkins, 2005). Since then, a number of revisions have been made. The latest model presented in the current paper was made in 1992 and cited in Ushida (2005). Figure 1 below demonstrates the model.

Socio-cultural milieu

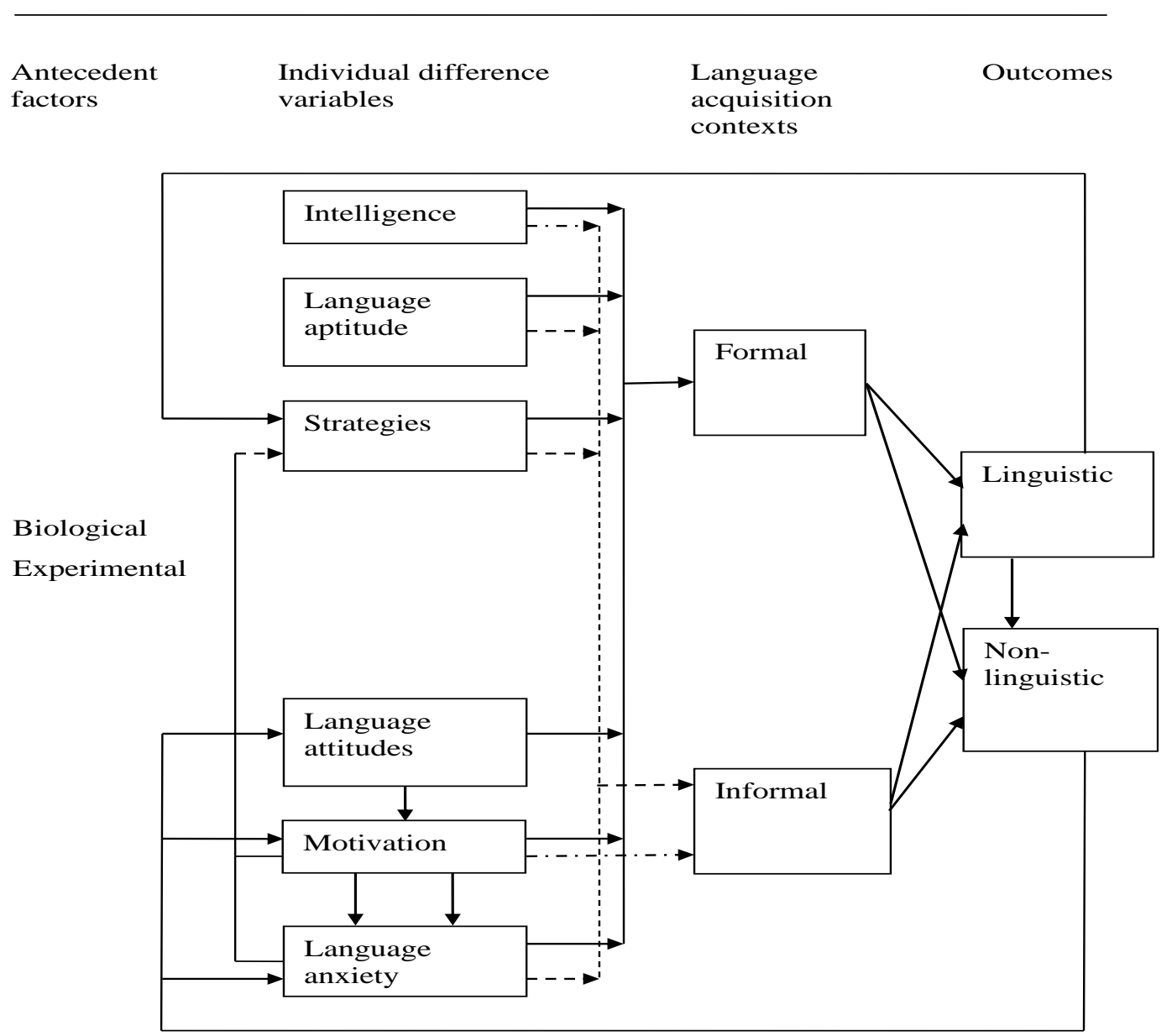

Figure 1: Representation of the Socio-educational model of second-language acquisition (Gardner and Maclntyre, 1992, cited in Ushida, 2005, p.51)

The model consists of four sections. Firstly, the socio-cultural milieu overrides all aspects of the model, i.e. the milieu in which "learners grow up determines their beliefs about language learning and culture" (Jenkins, 2005, p.11). The model suggests that there are two categories of antecedent factors: biological and experiential. These factors are important when investigating the role of variables in the process of language learning, including such categories as gender, age, previous language-learning experience, study abroad experience and so on. 
The second section covers individual difference variables, which are split into two groups: cognitive and affective. The cognitive individual difference variables are intelligence, language aptitude and strategies. Gardner considers them to be almost independent of each other. In contrast, the individual difference variables - language attitudes, motivation and language anxiety - are related. The model shows that language attitudes have an influence on motivation.

The third section is known as language acquisition contexts. The first sub-section, formal language acquisition contexts, are influenced directly by all the individual difference variables and indirectly through motivation by language attitudes. The second sub-section, informal language acquisition contexts, is directly influenced by motivation. Jenkins (2005) assumed that only motivated students would voluntarily seek out extra opportunities to practice the language. However, once in the informal situation, the other individual difference variables will have some influence over success in language learning. Finally, both formal and informal contexts have direct effects on both linguistic and non-linguistic outcomes. In addition, linguistic outcomes influence non-linguistic outcomes. However, Ushida (2005) suggests that more research needs to be done into the various variables and potential other variables associated with the model throughout the presentation of this model.

\subsection{Attitude}

\subsubsection{Definition of attitude}

There have been a number of definitions of attitude proposed by researchers. One of the most influential definitions of attitude is provided by Allport (1935, cited in Gibb, 1998), who describes attitude as a mental or neutral state of readiness, organized through experience, exerting a directive or dynamic influence on the individual's response to all objects and situations with which it is related. Focusing more on attitudes as explaining human behaviour, Kudo (1999) holds that an attitude is a disposition to respond favourably or unfavourably to an object, person, institution, or event. Baker (1992) also sees attitude as a hypothetical construct used to explain the direction and persistence of human behaviour. Meanwhile, Gardner (1985) gives a definition of an individual's attitude as "an evaluative reaction to some referent or attitude object, inferred on the basis of the individual's beliefs or opinions about the referent" (p.5).

Baker (1992) describes a similar three-part model of attitudinal components as presented in Figure 2.

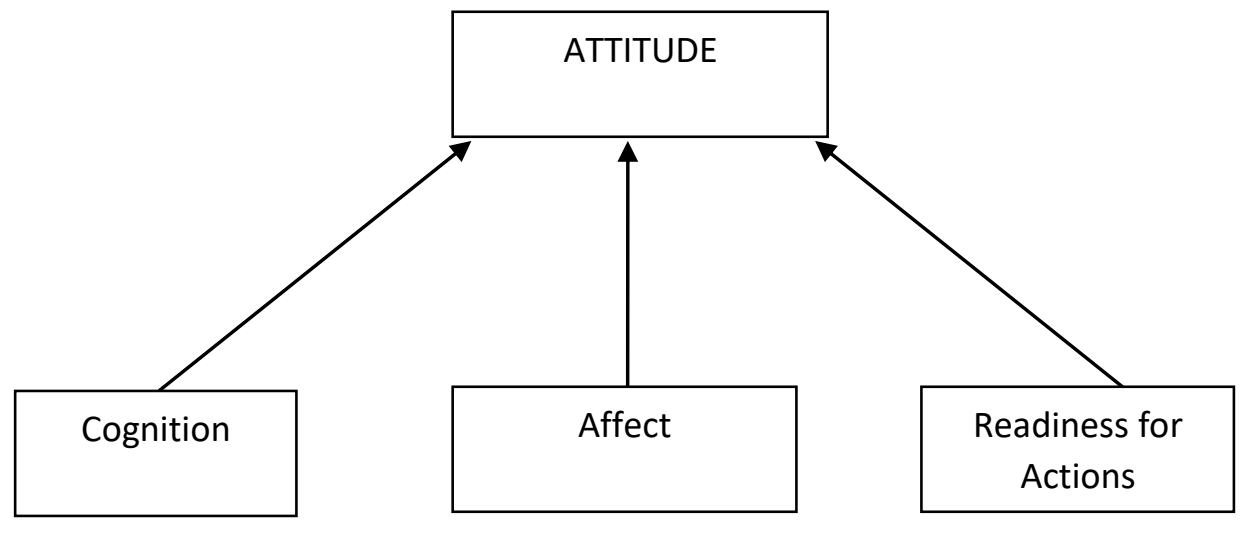

Figure 2: Attitudinal Components (Baker, 1992, p.13)

Field (1999) points out that the cognitive components of attitude refer to the beliefs and thoughts about the object. The cognitive components include belief about the language and belief about the people and community of that language. The affective components encompass more specific sentiments towards the object concerned. They refer to emotional reactions; they imply one's likes or dislikes concerning the attitudinal object or their degree. To make the explanation more convincing, Field takes an example that an individual who states that the position of English as a world language is desirable for effective cross-cultural communication will have positive attitudes towards learning English in terms of cognition.

However, as Field (1999) explains, the same individual may possess negative attitudes towards English in terms of effect; it is often the case that learners have had prior bad experiences at learning the language or are not interested in the cultures of English-speaking countries themselves. Therefore, it is clear that the components of attitude may be at odds with each other. Field also clarifies that the cognitive component refers, as is evident in the model shown above, to the willingness the individual possesses. To continue the example, he believes a learner who is hoping to find employment in an American company may be prepared to enrol in a language program, despite the negative affective component of attitude. 


\subsubsection{Language learning attitude}

\subsubsection{Concept of attitude in the language learning context}

In the section above, definitions of attitude in the literature are given. However, these definitions seem to be conceptualized in rather general terms and are not specific to the language learning context. In this section, attitudes will be seen in the language learning context.

It is claimed that, concerning attitudes in the language learning context, attitudes control an individual's motivation and are especially relevant for language learning because language learning includes many different aspects besides simply learning skills (Kudo, 1999). Kudo (1999) concludes that "attitudes may play a very important role in language learning, as they would appear to influence students' success or failure in their learning" (p.7). Klausmeier (1985), similarly, notes that attitudes influence how well student learn and how well they behave.

In his studies on Canadian students learning French, Gardner (1985) designates five dimensions of attitude with regard to second language achievement, which are: 1) attitudes toward learning French; 2) interest in foreign languages; 3) attitudes toward French Canadian; 4) evaluative reactions toward the French teacher; 5) evaluation of the French course. Among these five dimensions, learners' attitudes towards learning French and interest in foreign languages always seem to be more important than others.

Gardner (1985) believes that learners' attitudes toward learning the target language are expected to be more relevant to obtaining a high grade in target language proficiency than learners' interest in learning a foreign language or the people who speak the target language. He also proposes that there are crucial types of attitudes in the language learning context, and one of them is an attitude to the target language society. He considers that this type of attitude is essential, as learning a language requires students to incorporate another culture.

Stern (1983, cited in Rahman, 2005) distinguishes three types of attitudes in second language learning situation: (a) Attitudes towards the community and people who speak the L2 (group-specific attitudes), (b)Attitudes towards learning the language concerned; and (c) Attitude towards languages and language learning in general.

Baker (1992) also proposes that attitudes toward the language should be included in the concept of attitudes in the language learning context, claiming that successful learners tend to acquire positive attitudes toward the target language. Besides that, Cakici (2007) argues that the learners' positive attitude towards a language and towards the culture of that community facilitates learning, but an unfavourable attitude impedes learning.

Tremblay and Gardner (1995) expand Gardner's (1985) concept of attitudes in the language learning context by including attitudes toward the language learning situation in their measures of students' attitudes. Tremblay and Gardner also claim that attitudes toward the learning situation influence other elements of attitudes and motivation, stating that in the language learning situation, especially in schools, this type of attitude seems very important for students' success because students may perform better in the classroom if they have positive attitudes toward the learning situation.

According to Lightbown \& Spada (1999), the term 'attitude' in foreign language learning is generally used to refer to the attitude of the learners towards the target language society. This attitude is "a factor of learners' attitudes towards their own native culture the degree of ethnocentrism and the extent to which they prefer their own language over the one they are learning as a second language" (Brown, 1994, p.168). Crookes and Schmidt (1991) point out that this type of attitude may determine students' success in learning the language.

\subsubsection{Attitudes relevant to language learning research areas}

In his book titled 'Attitude and Language', Baker (1992) states that the phrase 'language attitudes' is an umbrella term. The question is which attitudes should be highlighted in a specific language situation for specific research. Language attitudes might be researched in language teaching, language learning, language communities, language itself, parents' language attitudes, or other aspects. Coming to his extensive studies on language attitudes from his interest in bilingualism and the conservation of minority languages, Baker lists various attitudes of interest to foreign language learning (FLL) research: (1) attitude to language variation, dialect and speech style; (2) attitude to learning a new language; (3) attitude to a specific minority language (e.g. Irish); (4) attitude to language groups, communities and minorities; (5) attitude to language lessons; (6) attitude to the uses of a specific language; (7) attitude of parents to language learning; (8) attitude to language preference.

Examining a variety of research on attitudes in 2LL and FLL, Larsen-Freeman \& Long (1991), identify the five areas: (1) Parents: parents' attitudes towards the target language community affect not only children's attitudes but also achievement; (2) Peers: the attitudes of peers affect learners' acquisition of a second language; (3) Learning situation: the learners' attitudes towards the 
learning situation affect their degree of success; (4) Teachers: teachers' attitudes towards learners affect the quality and quantity of the learning which takes place; (5) Ethnicity: ethnicity can determine attitudes and behaviour toward members of other groups, and these, in turn, might affect achievement.

With so many relevant or possibly relevant attitudes to consider in the course of researching 'attitudes to and motivation for learning English', Seki (2004) suggests that it is necessary to determine which sort of attitudes will be focused upon clearly.

\subsection{Motivation}

\subsubsection{Definition of motivation}

'Motivation' is a term frequently used in both education and research fields. Different interpretations of the definition of motivation depend on various psychological perspectives of human behavior. In spite of the numerous definitions of motivation that have been proposed, "it is rather surprising how little agreement there is in the literature with regard to the exact meaning of this concept" (Dornyei, 1994, p.274). Therefore, the definitions of motivation from contemporary research representing different points of view will be discussed in the following paragraphs.

Brown (1994) gives the definition of motivation as "inner drive, impulse, emotion, or desire that moves one to a particular action" (p.152). Keller (1983, cited in Chang, 1994) believes that ability and motivation are the major factors of variation in educational success: ability refers to what a person can do; motivation, to what a person will do. Similarly, Demir (2000) defines motivation as the tendency to expend effort to achieve goals. Harmer (1991) also states that motivation is some kind of "internal drive that encourages somebody to pursue a course of action" (p.3).

Some psychologists define motivation in terms of certain needs. Maslow (1954, cited in Abisamra, 2001) categorizes five specific human needs: physiological needs, safety needs, belonging and love needs, self-esteem needs and self-actualization needs. Ausubel (1968, cited in Brown, 1994, p.152) identified six following needs undergirding the construct of motivation proposed by (1) The need for exploration, for seeing "the other side of the mountain," for probing the unknown; (2) The need for manipulation, for operating on the environment and causing change; (3) The need for activity, movement and exercise, both physical and mental; (4) The need for stimulation, the need to be stimulated by the environment, by other people, or by ideas, thoughts, and feelings; (5) The need for knowledge, the need to process and internalize the results of exploration, manipulation, activity, and stimulation, to resolve contradictions, to quest for solutions to problems and for self-consistent systems of knowledge; (6) Finally, the need for ego enhancement, for the self to be known and to be accepted and approved by others.

Meanwhile, the psychologist Keller $(1983$, cited in Chang, 1994) defined motivation as the choices people make as to what experiences or goals they will approach or avoid and the degree of effort they will exert in that respect. Keller's theory of motivation includes four major determinants of motivation: (a) interest, (b) relevance, (c) expectancy and (d) outcomes.

Relating motivation to learning a second language (L2), Gardner (1985) proposed "motivation is a term which is often used with respect to second language learning as a simple explanation of achievement" (p.10). Continuously, Dornyei (1994) indicated that L2 motivation was "a multi-faceted construct and describing its nature and its core features requires particular care" (p.274). Gardner's (1985) definition of motivation in language learning was the "effort plus desire to achieve the goal of learning the language plus favourable attitudes toward learning the language" (p.10). Similarly, Dornyei (1994) conceptualized language learning motivation as including three components: motivational intensity, desire to learn the language and an attitude towards the act of learning the language.

\subsubsection{Distinction between attitude and motivation}

Rahman (2005) distinguishes between attitude and motivation, defining 'attitude' as the persistence shown by the learner in striving for a goal, whereas 'motivation' is seen in terms of the overall goal or orientation. Raman (2005) argues one should not necessarily expect a relationship between the two. However, Gardner (1985) suggests that attitudes are related to motivation by serving as supports of the learner's overall orientation.

Baker (1992), discussing the distinction between 'attitude' and 'motive' in foreign language education, notes that these two terms "often appear without discussion of the extent of overlap and difference" (p.14). Gardner \& Lambert (1972, cited in Seki, 2004) define 'motivation' as the second-language learner's overall goal and orientation and 'attitude' as the learner's persistence in striving to the goal. However, Seki (2004) views that 'motivation' and 'attitude' are not thereby clearly delineated from one another, in that the learner's motivation for language study would be determined by his attitudes and readiness to identify and by his orientation to the whole process of learning a foreign language.

Obviously, it is widely accepted that attitudes are object-specific, and motivation has particular actions as its goals (Baker, 1992; Seki, 2004; Ushida, 2005). Johnstone (2001), for example, wrote that "attitudes have objects as their points of reference, e.g., a 
positive attitude to school, and continues that 'motivation has goals rather than objectives as its point of reference" (p.120). Therefore, individuals are assessed on whether they have negative or positive attitudes to a certain object. On the other hand, motivation is either present (at some strength) or absent, rather than negative or positive.

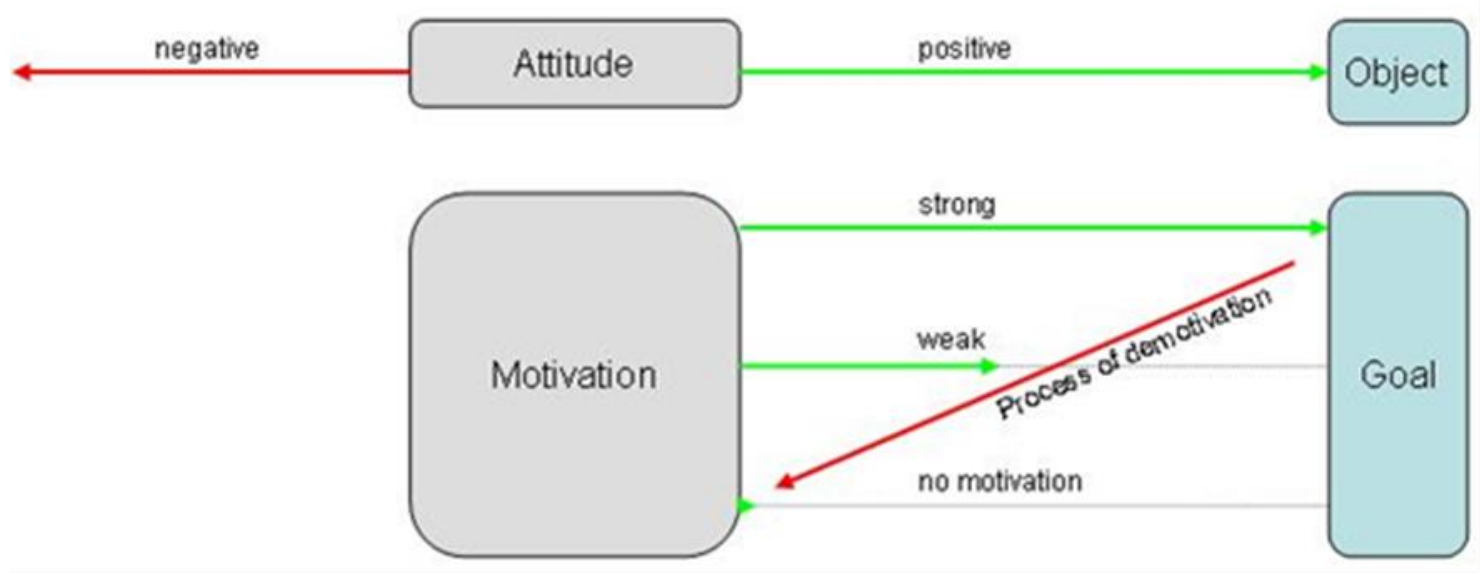

Figure 2: Distinction between attitude and motivation (Seki, 2004, p.58)

\subsubsection{Motivation in language learning}

\subsubsection{Gardner's motivation theory}

Much of the research on second language learning motivation has been inspired by two Canadian psychologists, Gardner and Lambert and depends primarily on a social-psychological explanation of motivation since the 1950s (Crookes \& Schmidt, 1991). The study of $\mathrm{L} 2$ motivation became a distinctive research topic after Gardner and Lambert published a comprehensive summary of the result of a more than ten-year-long research program. They constructed a framework for L2 motivation which has dominated the language learning motivation scene for about three decades (Chang, 1994). There are three areas in Gardner's model: (a) the construct of the integrative motive; (b) the Attitude/Motivation Test Battery (AMTB) and (c) the socio-educational model (Dornyei, 1994).

Using Gardner's (1985) concept, attitudes relating to the language itself play an important role in motivation. The language features could shape attitudes such as its sound, the way of writing and so forth. Other components, such as the learner attitudes toward learning a language in general and feelings toward the teacher, affect learner motivation to learn the language. Gardner (1985) believed that "motivation in the present context refers to the combination of effort plus desire to achieve the goal of learning the language plus favourable attitudes toward learning the language" (p.10).

Orientation is another concept that Gardner (1985) proposed in the discussion of motivation. Motivation refers to the directed, reinforcing effort individual learners make to learn the language; orientation is a class of reasons for studying a second language. Gardner (1985) pointed out that motivation is goal-directed; orientation explains why a learner has a goal.

Gardner and Lambert $(1972$, cited in Chang, 1994) delineated the dichotomy between integrative and instrumental orientation. Integrative orientation is identified with the individual's desire for culture or linguistic integration. Gardner (1985) asserted that since integrative orientation reflects a "positive non-ethnocentric approach to the other community" (p.134), it probably relates as strongly to attitudes toward the community as it does to motivation to learn their language. Instrumental orientation refers to learning the language for an instrumental purpose, such as getting a better job, earning more money, passing an examination and so on (Gardner, 1985). Gardner and Maclntyre (1993) considered integrative and instrumental orientations as independent of each other. They could be treated as two separate variables.

Gardner and his associates believed integrative orientation would be a better predictor of eventual proficiency than would instrumental orientation. Gardner and Lambert developed the Attitude/Motivation Test Battery (AMTB) in 1959 (Chang, 1994). In 1975, Gardner and Smythe redeveloped the test and it became the instrument of choice in second language studies involving motivation (Chang, 1994). The influence was such that other potential theories of motivation were almost completely ignored. However, since 1990 second and foreign language researchers have started to challenge Gardner's motivation theory and discussed other theories of motivation in language learning (Dornyei, 1994; Noels et al., 1999; Skehan, 1989). While numerous dominant models have been constructed, Gardner's AMTB keeps still widely used in many studies. The results were mixed and led to much discussion about the applicability of integrative and instrumental motivation in second and foreign language learning. 
Gardner's theory is essential to keep in mind but as several researchers have pointed out "its emphasis is clearly on the social aspects of motivation rather than on the role of motivation in the classroom" (Dornyei, 1994, p.274). Thus, many researchers have attempted to modify and adapt Gardner's theory and other theories of motivational psychology and apply them to educational situations.

\subsubsection{Crookes and Schmidt's approach}

Researchers Crookes and Schmidt (1991) were some of the first to question Gardner's approach stating that the empirical evidence is not clear enough to support the notion that integrative motivation is a cause and affects the second language achievement. They also stated that its emphasis on social aspects is a limiting feature and discusses the need for more suited approaches to L2 education. Crookes and Schmidt identified a clear need to research and classify L2 learning motivation as it relates directly to the classroom.

Crookes and Schmidt (1991) identified four areas of L2 motivation: (1) the micro-level, (2) the classroom level, (3) the syllabus level, and (4) the fourth level involving factors from outside the classroom. The micro-level involves the cognitive processing of L2 input. At the micro level, learner motivation is evidenced by the amount of attention given to the input. The classroom level includes the techniques and activities employed in the classroom. Crookes \& Schmidt apply tenets of expectancy-value and selfdeterministic theories to this level stating that the expectancy of success and amount of control over activities contributes to learner motivation. The syllabus level refers to the choice of the content presented and can influence motivation by the level of curiosity and interest aroused in the students. Finally, factors from outside the classroom involve informal interaction in the L2 and long-term factors.

\subsubsection{Dornyei' framework of motivation}

Dörnyei (1994) following Crookes' and Schmidt's initiative, developed yet another framework of motivation, which dealt specifically with motivation in the language classroom presented in Table 1.

His taxonomy of motivation is comprised of three levels: (1) the Language Level, (2) the Learner Level, and (3) the Learning Situation Level. The Language level is the most general level which focuses on "orientations and motives related to various aspects of the L2" (p.275). At this level, the motives and orientations determine the language studied and the most basic learning goals. Dornyei identifies motivation at this level using the concept of orientation introduced by Gardner. The Learner level involves the influence of individual traits of language learners. Motivation is influenced at the Learner Level by the learner's need for achievement and self-confidence. The Learner Level is concerned with internal, affective characteristics of the learner related to expectancy. Motivation at the Learning Situation Level is influenced by several intrinsic and extrinsic motives that are coursespecific, teacher-specific, and group-specific.

Table 1: Components of foreign language learning motivation (Dornyei, 1994, p.280)

\begin{tabular}{|c|c|}
\hline LANGUAGE LEVEL & $\begin{array}{l}\text { Integrative Motivational Subsystem } \\
\text { Instrumental Motivational Subsystem }\end{array}$ \\
\hline LEARNER LEVEL & $\begin{array}{l}\text { Need for Achievement } \\
\text { Self-Confident } \\
\text { *Language Use Anxiety } \\
\text { *Perceived L2 Competence } \\
{ }^{*} \text { Casual Attributions } \\
{ }^{*} \text { Self-Efficacy }\end{array}$ \\
\hline LEARNING SITUATION LEVEL & \\
\hline Course-Specific Motivational Components & $\begin{array}{l}\text { Interest } \\
\text { Relevance } \\
\text { Expectancy } \\
\text { Satisfaction }\end{array}$ \\
\hline Teacher-Specific Motivational Components & $\begin{array}{l}\text { Affiliative Drive } \\
\text { Authority Type } \\
\text { Direct Socialization of Motivation } \\
\text { *Modelling } \\
\text { *Task Presentation } \\
\text { *Feedback }\end{array}$ \\
\hline
\end{tabular}




\section{Group-Specific Motivational Components \\ Goal-orientedness \\ Norm \& Reward System \\ Group Cohesion \\ Classroom Goal Structure}

The course specific motivational components relate to the class syllabus, the materials used, the teaching method, and the learning task. Dornyei uses the conditions presented by Keller and later by Crookes and Schmidt (1991) to describe these conditions: Interest, Relevance, Expectancy, and Satisfaction. The teacher specific motivational components are the characteristics of the teacher and the teaching style that affect learner motivation. The group specific motivational components refer to the social influences on motivation from the collective group that the learner is a part of.

\subsubsection{Self-determination theory of motivation}

Deci and Ryan's (1985) self-determination theory has a prevailing influence on both psychology and language education (Liuoliene and Metiuniene, 2006). Self-determination theory was divided into intrinsic and extrinsic motivation. The selfdetermination approach identifies two types of motivation: intrinsic and extrinsic. Intrinsic motivation refers to motivation to perform an activity simply for the pleasure and satisfaction that accompany the action and is considered to be highly selfdetermined in the sense that the reason for doing an activity is linked solely to the individual's positive feelings while performing the task (Noels et al. 1999). People who are intrinsically motivated feel that they are doing an activity because they have chosen to do so voluntarily and because the activity represents a challenge to their existing competencies and requires them to use their creative capabilities (Carreira, 2005). Another example of an intrinsically motivated student is that he or she finds delight in learning a new way to express an idea in the $L 2$.

Ryan and Deci (2000) demonstrate that an intrinsically motivated person does an activity for its inherent satisfactions rather than for some separable consequence. They also claim that "when intrinsically motivated a person is moved to act for the fun or challenged entailed rather than because of external prods, pressures or rewards" (p.56). On the other hand, extrinsic motivation implies a lack of self-determination, which leads to the behaviours performed not because of inherent interest but because of extrinsic stimuli (Chang, 1994). In brief, extrinsic motivation is motivation based on external rewards. These external rewards can be "money, prizes, grades, and even certain types of positive feedback" (Brown, 1994, p.156). The rewards can also be expected in the future for an EFL learner, being able to immigrate and so forth. Ryan and Deci (2000), meanwhile, remarked that "extrinsic motivation is a construct that pertains whenever an activity is done in order to attain some separable outcome" (p.60). They accentuate that extrinsic motivation contrasts with intrinsic motivation and extrinsic motivation can vary greatly in the degree to which it is autonomous. To support their argument, Ryan and Deci (2000) give two examples of extrinsic motivation: The first one is about a student who does his homework only because he is doing the work in order to attain the separable outcome of avoiding sanctions; the other example of an extrinsically motivated student is that she does the work because she personally believes it is valuable for her chosen career, so she does the work for its instrumental value rather than because she finds it interesting.

The final motivational concept proposed by Deci \& Ryan (1985, cited in Ryan and Deci, 2000) in theory is a motivation or lack of any kind of motivation. This differs from demotivation, which "refers to a loss of motivation rather than the state of lacking any motivation" (Seki, 2004, p.65). A person is considered motivated when he or she does not see a relation between his or her actions and their consequences but rather sees the consequences as arising from factors beyond his or her control (Noels et al. 1999).

In general, some researchers agree that extrinsic motivation may undermine intrinsic motivation, particularly if a learner receives the rewards as controlling rather than as providing information about his/her competence. Intrinsic motivation is worth promoting in $\mathrm{L} 2$ learning in that it can foster creativity, conceptual learning, desire for challenges, and enjoyment. Accordingly, an individual learner who has an intrinsic or extrinsic motivation is likely to feel positive about the activity and put in more effort over a longer period of time (Chang, 1994).

\section{Conclusion}

As discussed above, it was confirmed by the researchers that attitude and motivation play a crucial role in language learning and that attitude and motivation affect how well students learn a language. If students possess a good attitude toward learning the language, it will accelerate learning. And if learners are well motivated, they will perform well in learning.

Among the motivational theories, self-determination theory and Gardner's theory attract the most attention. According to Gardner's theory, there are two types of motivation: integrative and instrumental. Integrative motivation refers to a desire to communicate with community members and become similar to them. Instrumental motivation is associated with a desire to learn a language for pragmatic gains such as getting a job. Meanwhile, self-determination theory differentiates intrinsic and 
extrinsic motivation. Intrinsic motivation refers to motivation to do an activity simply for pleasure and satisfaction, and extrinsic motivation is the motivation that based on external rewards such as money, prize or grades. Hopefully, this paper's review will help clarify and shed light on the theory about attitude and motivation in foreign language learning on these aspects.

\section{References}

[1] Abisamra, N. S. (2001). Affect in language learning - motivation. Retrieved July 07, 2019 from: http://www.nadasisland.com/motivation/\#top

[2] Baker, C. (1992). Attitudes and language. Clevedon: Multilingual Matters.

[3] Brown, H. (1994). Principles of language learning and teaching (3rd ed.). New Jersey: Prentice Hall Regents.

[4] Cakici, D. (2007). The attitudes of university students towards English within the scope of common compulsory courses. Retrieved June 14 ${ }^{\text {th }}$, 2009 from: http://www.gefad.gazi.edu.tr/window/dosyapdf/2007/3/2007-3-21-35-21-35.pdf

[5] Carreira, J. M. (2005). New framework of intrinsic/extrinsic and integrative/instrumental motivation in second language acquisition. The

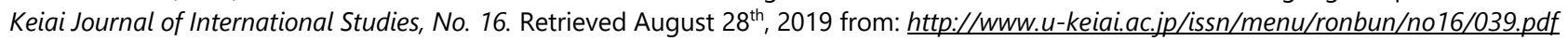

[6] Chang, C. Y. (1994). An overview of research on language learning motivation. The Modern Language Journal, 78(1), 12-28. Retrieved June $24^{\text {th }}, 2019$ from: $w w w . f e u . e d u . t w / a d m s / a a o / . . /$ 遠東學報二十卷四期927.pdf

[7] Clement, R., Dornyei, Z., \& Noels, K. A. (1994). Motivation, self-confidence and group cohesion in the foreign language classroom. Language learning, 44(1), 417-448.

[8] Crookes, G. \& Schmidt, R. (1991). Motivation: Reopening the research agenda. Language Learning, 41(1), 469-512.

[9] Demir, B. (2000). The influence of various motivational factors in foreign language learning. Retrieved July $16^{\text {th }}, 2019$ from: http://yadem.comu.edu.tr/3rdELTKonf/pos bora demir.htm

[10] Dornyei, Z. (1994). Motivation and motivating in the foreign language classroom. The Modern Language Journal, 78(3), $273-284$.

[11] Field, G. (1999). Attitudes, motivation, language preference and the ELT profession: A study of a private language school in Yokohama, Japan. Retrieved May 17 th 2019 from: http://www.surrey.ac.uk/ALRG/dissertations/pdf/Field G 1999.pdf

[12] Gardner, R. C. (1985). Social psychology and second language learning. London: Edward Arnold.

[13] Gibb, M. (1998). A comparative study of attitudes towards varieties of English held by professionals and tertiary level students in Korea. Retrieved June $24^{\text {th }}, 2019$ from: http://www.surrey.ac.uk/ALRG/dissertations/pdf/Gibb M 1998.pdf

[14] Harmer, J. (1991). The pratice of English language teaching. London and New York: Longman.

[15] Jenkins, A. C. (2005). EFL motivations and teacher preference: a survey of Japanese university students in Niigata. Retrieved December 20 2018 from: http://www.surrey.ac.uk/ALRG/dissertations/pdf/Jenkins A 2005.pdf

[16] Johnstone, R. (2001). Research on language teaching and learning: 2000. Language Teaching, 34(1), 143-165.

[17] Klausmeier, J. H. (1985). Educational psychology. New York: Harper \& Row.

[18] Kudo, K. (1999). Oral self-expression activities as a facilitator of students' positive attitudes and motivation: a case study of Japanese secondary school students. Retrieved May 15 th 2019 from: http://www.surrey.ac.uk/ALRG/dissertations/pdf/Kudo K 1999.pdf

[19] Larsen-Freeman, D. \& Long, M. (1991). An introduction to second language acquisition research. London: Longman.

[20] Lightbown, P. \& Spada, N. (1999). How languages are learned. Oxford: Oxford University Press.

[21] Liu, M. (2005). Review of Gardner's motivation theory. Retrieved February 20 ${ }^{\text {th }}, 2019$ from: http://www.ijee.org/mllw/0501qien/02-0105.htm

[22] Liu, M. (2007). Chinese students' motivation to learn English at the tertiary level. Asian EFL Journal, 9(1), 126-146. Retrieved June 16 ${ }^{\text {th }}$, 2019 from: http://www.asian-efl-journal.com/March $07 \mathrm{ml}$. php

[23] Liuolienè, A. \& Metiūnienè, R. (2006). Second language learning motivation. Retrieved June $20^{\text {th }}, 2019$ from: www.coactivity.vgtu.lt/upload/filosof zurn/a liuoliene metiuniene filologija nr2.pdf

[24] Noels, K. A., Clement, R. \& Pelletier, L. G. (1999). Perceptions of teachers' communicative style and students' intrinsic and extrinsic motivation. The Modern Language Journal, 83(1), 23-34.

[25] Rahman, S. (2005). Orientations and motivation in English language learning: a study of Bangladeshi students at Undergraduate level. The Asian EFL Journal, 7(1), 1-26.

[26] Ryan, R. M. \& Deci, E. L. (2000). Intrinsic and extrinsic motivations: classic definitions and new directions. Retrieved August $14^{\text {th }}, 2019$ from: http://www.idealibrary.com

[27] Seki, T. (2004). Attitudes to and motivation for learning English in Japan with special reference to first-year university students. Retrieved May 23 ${ }^{\text {rd }}$, 2019: https://dspace.stir.ac.uk/dspace/bitstream/1893/60/1/Thesis TeakoSeki

[28] Tremblay, P. F. \& Gardner, R. C. (1995). Expanding the motivation construct in language learning. The Modern Language Journal, 79(4) 505520.

[29] Ushida, E. (2005). The role of students' attitudes and motivation in second language learning in online language courses. CALICO Journal, 23(1), 49-78. Retrieved July $15^{\text {th }}, 2019$ from: https://www.calico.org/html/artical 131.pdf 